\title{
The Causes and Consequences of Color Vision
}

\author{
Ellen J. Gerl • Molly R. Morris
}

Published online: 2 October 2008

(C) Springer Science + Business Media, LLC 2008

\begin{abstract}
The ability to see colors is not universal in the animal kingdom. Those animals that can detect differences in the wavelengths of the electromagnetic spectrum glean valuable sensory information about their environment. They use color vision to forage, avoid predators, and find highquality mates. In the past, the colors that humans could see clouded scientists' study of animals' color perception. Leaving that bias behind has led to new insights about how and why the color vision of animals evolved. This paper provides a brief introduction to color vision, the genetics of color vision in humans, what colors other animals see, and how scientists study color vision. We examine the consequences of having color vision, including speciation, loss of olfactory capabilities, and sexual selection.
\end{abstract}

Keywords Adaptive coloration - Color vision - Crypsis . Evolution · Eye - Perception - Sexual selection .

Visual communication

\section{Introduction: Seeing a World in Color}

Most humans see the world in color. Our visual system has evolved to let us perceive a rich color palette, one that can make sense of subtle blue hues in a night sky as well as brilliant reds and yellows in a bird's plumage. Somewhat naturally, we have assumed that other animals sense colors much as we do. What is more, it seemed that animals lacking color vision had a sensory deficit. But scientists studying color vision are putting both those assumptions at bay. Recent behavioral, phylogenetic, and neurological studies,

E. J. Gerl $(\bowtie) \cdot$ M. R. Morris

Ohio University,

Athens, OH, USA

e-mail: gerl@ohio.edu among others, indicate that some animals perceive a multicolored world invisible to humans, whereas others, whose visual systems evolved to operate in dim light, view their world in textured shades of black and white.

The realization that humans do not see the same color world that most animals see has been important for behavioral and evolutionary studies of a wide array of signals that include crypsis, mimicry, warning coloration, fruit and flower coloration, and sexual dimorphism (to name a few, Endler 1990, Bennett et al. 1994). What is important for the evolution of these traits is the color vision of the intended audience of these signals, be that a predator, pollinator, or potential mate. Indeed, it has been suggested that color is not an inherent property of an object but a property of the visual system of the organism that perceives it (Endler 1978). In other words, the exact same wavelength spectra reflecting off an object will be perceived as different colors depending on the absorption spectra of an animal's photoreceptors.

In this paper, we provide a brief introduction to color vision, the genetics of color vision in humans, what colors we think other animals can see, and how scientists study color vision. We then examine the consequences of color vision for communication between plants and animals as well as males and females, and then the confounding selection pressures of communicating with conspecifics while hiding from predators. Finally, we examine the question of why all organisms do not see colors and look at some animals whose visual capabilities defy expectations.

\section{Some Definitions}

For an organism to see colors, its visual system must compare signals that originate in different photoreceptors in 
the retina. In Eye, Brain and Vision, researcher David Hubel calls the human retina an amazing structure: "It translates light into nerve signals, allows us to see under conditions that range from starlight to sunlight, discriminates wavelength so that we can see colors, and provides a precision sufficient for us to detect a human hair or speck of dust a few yards away" (Hubel 1988). To understand how the retina extracts visual information from the environment, it is helpful first to understand some basic terms.

The retina records and compares light intensities using two basic kinds of photoreceptors: rods and cones. Rods allow for vision in dim light and have only one photopigment, whereas cones are responsible for color perception and have more than one class of photopigments. The genes crucial to production of the photopigments in cones and rods are called opsins (see side article, "Genetics of Human Color Vision").

Trichromacy, the variety of color vision found today in most Old World primates including humans, describes vision based on three classes of cone photoreceptors - in short, the ability to discern reds, greens, and blues. Dichromatic vision, then, relies on data from only two classes of cones. A higher percentage of human males than females are considered functional dichromats, which still allows for color discrimination (Fig. 1a); however, their color deficiency is commonly called color blindness. In the most common form of dichromacy in humans, individuals cannot differentiate between reds and greens (Hubel 1988). When only one class of cones is functioning, the organism

\section{a Inheritance of Color Blindness in Men and Women}

\begin{tabular}{|l||l||l||}
\hline \hline Sex & Color Blind & Normal Vision \\
\hline \hline Male & $\mathbf{X}^{\mathbf{0}} \mathbf{Y}$ & $\mathbf{X}^{+} \mathbf{Y}$ \\
\hline \hline Female & $\mathbf{X}^{\mathbf{0}} \mathbf{X}^{\mathbf{0}}$ & $\mathbf{X}^{+} \mathbf{X}^{+} \mathbf{X}^{+} \mathbf{X}^{\mathbf{0}}$ \\
\hline
\end{tabular}

\section{b Inheritance of LWS alleles in Men and Women}

\begin{tabular}{|l||l|l|}
\hline \hline Sex & Tetrachromatic Vision & Trichromatic Vision \\
\hline \hline Male & & $\mathbf{X}^{++} \mathbf{Y} \quad \mathbf{X}^{+} \mathbf{Y}$ \\
\hline \hline Female & $\mathbf{X}^{++} \mathbf{X}^{+}$ & $\mathbf{X}^{+} \mathbf{X}^{+} \quad \mathbf{X}^{++} \mathbf{X}^{++}$ \\
\hline
\end{tabular}

Fig. 1 Schematic of the genetic basis of color vision in humans: a Color blindness is a recessive sex-linked trait found on the $\mathrm{X}$ chromosome. Sex-linked genes located on $\mathrm{X}$ chromosome: plus sign normal vision (dominant), $o$ color blindness (recessive); b Sex-linked genes located on $\mathrm{X}$ chromosome: single plus sign LWS allele SER $(557 \mathrm{~nm})$, double plus sign LWS allele ALA $(552 \mathrm{~nm})$. The difference in the absorption frequency between the SER and ALA alleles allows females with both alleles (heterozygotes) to see more colors than males and females with trichromatic color vision (Deeb and Motulsky 1996) has monochromatic vision; since color vision depends on a comparison of signals, this type of vision does not allow for color perception.

The physiological and genetic makeup of various animals' retinas varies widely- the types of photoreceptors present and ratio of cones to rods are just two examplesand thus, not surprisingly, their visual capabilities show great diversity.

\section{What Colors do Animals See?}

Many differences exist between what humans and other animals can see. Some animals, among them frogs, fish, some rodents, and many marsupials, can see ultraviolet (for reviews see Bennett et al. 1994). However, the differences between what humans see and what other animals see are likely to go well beyond our inability to see ultraviolet.

Research suggests that birds may have the most sophisticated visual system of any vertebrate. They likely see hues that we cannot imagine. Many birds have five classes of cones, and some species of birds see ultraviolet. In addition, a bird's visual system includes oil droplets thought to act as filters of light entering individual cones (Bennett et al. 1994). Scientists do not know how this increased dimensionality enhances the colors that birds perceive. Many reptiles have color vision, and researchers have learned that diurnal lizards have four types of cones and colored oil droplets, suggesting they probably have tetrachromatic color vision (reviewed by Roth and Kelber 2004).

Old World monkeys, apes, and humans all enjoy trichromatic color vision (Jacobs 1993), but most terrestrial mammals are cone dichromats, and like the small percentage of humans with dichromatic vision, they likely can distinguish only a limited number of colors (Peichl et al. 2001; reviewed by Jacobs 1993). Of the ungulates studied to date, such as horses, pigs, goats, cows, sheep, and deer, all have the photopigment basis for dichromatic color vision (Carroll et al. 2001). Similarly, researchers studying the color vision of dogs have confirmed they are dichromats. In addition, they have found that the cones present in the central area of a dog's retina are low in number, probably representing less than $10 \%$ of the total photoreceptors present. Interestingly, the same area of the human retina consists predominately of cones. Presumably, the canine visual system's greater reliance on rod photoreceptors allows a dog to function well in dim light, making it a more effective predator in its ecological niche (Neitz et al. 1989; Miller and Murphy 1995).

Even among humans, men and women may perceive colors differently. For instance, using genetic analysis and behavioral tests, researchers at the University of California San Diego explored gender-linked differences in color 
perception, in particular, the sensory experience of women who have an extra photopigment in their retinas. Some estimates suggest four-photopigment females represent up to $50 \%$ of the female population; $8 \%$ of males are presumed to have four-photopigment retinas (Neitz et al. 1998). Their study suggested that women with four-photopigment retinas perceived more chromatic bands in the typical rainbow spectrum than either men or women with trichromatic retinas (Jameson et al. 2001).

Other scientists' work on the genes involved in human color vision suggests that even among those of us who can discriminate red colors, we may be perceiving different reds. Researcher Samir Deeb and colleagues at the University of Washington have been studying how the genetic makeup of an individual's retina affects color perception. In one study, they learned that approximately $40 \%$ of men with normal color vision had the amino acid alanine in their red pigment, whereas $60 \%$ had a different amino acid, serine, at the same spot (Winderickz et al. 1992, Fig. 1b). The pigment with serine is shifted to red, the one with alanine to green, explained Deeb in a phone interview. "It's not a big shift but still really quite exciting," he said. "It affects not only normal color vision, but also the severity of abnormal color vision."

\section{How Scientists Study Color Vision in Different Organisms}

Humans' perception of color has shaped how scientists have studied color vision, leading to some misconceptions concerning why and how color vision evolved (Endler 1990; Bennett et al. 1994). The differences between the color vision of humans and the animals that the color patterns are directed toward could mean the difference between assuming an animal that is "brightly" colored is conspicuous, possibly attempting to attract a mate, and that the colors function as camouflage (Marshall 2000). Information gleaned from genetic studies is helping us rethink other assumptions about how animals perceive color. In the past, much of the psychological literature attributed differences between how women and men process color information to environmental factors; for instance, young girls' ability to identify primary colors by name better than young boys was explained by their greater verbal ability and interest in colors. But recent opsin gene analyses show that many females possess more than three photoreceptor pigments, indicating that there may be a genetic explanation for gender-based color perception differences (Jameson et al. 2001, See Fig. 1b) As new techniques and methods of examining colors and color vision are developed that do not rely on human color vision, we learn more about the diversity of colors and color vision across animals. Indeed, we have used these methods to learn more about color vision within humans as well (see above).
The measurement of colors independently of human vision has recently become practical with the use of spectoradiometers. While these devices can make measurements of the physical properties of colors, even the way in which the data is scored can introduce human bias if the measurements are then converted into color codes based on human perception. Scores that are independent of our perception of colors have been developed (see Endler 1990) and make it possible to examine the ability of animals with color vision perception very different from ours. But how do scientists determine the differences between spectra other animals can perceive? Behavioral studies, one of the most reliable methods scientists use to determine what colors an animal can see, do not require complex molecular techniques or sophisticated machines. In the early 1900s, Karl von Frisch, an Austrian naturalist and winner of the Nobel Prize, questioned the commonly held assumption that fish were color-blind. One of his main opponents was Karl von Hess, the director of Munich Eye Clinic, who primarily disagreed with von Frisch's reasoning that natural selection would act on the senses of animals. Von Frish was able to demonstrate that fish could indeed perceive colors by training minnows to respond to colored objects. Today, scientists still use behavioral color discrimination experiments to determine what colors animals can see. To study the color vision of nocturnal geckos, for instance, researchers trained the geckos to choose between two cues, blue and grey stimuli, rewarding them with untreated "tasty" crickets or negatively reinforcing choices with treated "untasty" crickets (Roth and Kelber 2004).

Not all organisms lend themselves to behavioral studies. Another method to examine the potential for color vision employs molecular genetic analyses to determine what opsin genes an organism possesses. Genes that code for the different retinal photopigments sensitive to particular wavelengths of light can be detected with DNA sequencing. Therefore, it is possible to determine with a small piece of tissue if an animal possesses the genes necessary to make the photopigments to detect different colors. This method helps us learn about animals difficult to study in the wild, like the endangered aye-aye. Researchers who were able to obtain DNA samples of eight aye-ayes available at a few international research institutions gained a better understanding of how this nocturnal primate retained some color vision (Perry et al. 2007).

It is important to note, however, that having a gene for a particular protein does not necessarily mean that the information in that gene is used to actually make that protein. In other words, not all genes that an organism has are expressed all the time, or in some cases ever. Some genes are only expressed during development, and others are not expressed unless there is another gene or a particular environment present. Therefore, a third method to determine 
color perception of an animal involves postmortem analyses to see if the photopigments necessary to detect certain colors are present in their retinas. This may seem like the ultimate method to answer the question "what colors do animals see?" but it is not. While the number and spectral sensitivities of the photopigments usually give scientists a pretty good idea of what colors an animal can detect, behavioral experiments have shown that this is not always the case. The butterfly Vanessa atalanta has three photopigments but was unable to discriminate colors in the long wavelength range, while Heliconius erato, a butterfly that also has three photopigments, was able to discriminate colors in the long wavelength range (Zaccardi et al. 2006). In the case of these butterflies, the answer to this discrepancy appears to be molecules other than opsins found in the retina cells that can filter light and modify spectral sensitivity. However, it is also possible that the neurological processing of the information provided by the eyes may differ across organisms. Indeed, one study shows that the mammalian brain is flexible enough to readily make use of information from opsin proteins (Jacobs et al. 2007). Jacobs and his research colleagues genetically engineered mice to have an additional, slightly different long-wavelength-sensitive (L) pigment; through behavioral tests, they discovered the mice could immediately distinguish a broader spectrum of colors. Therefore, it is important to remember that evidence for color vision is likely best derived from a combination of studies, including molecular, physiological, and behavioral.

Finally, our understanding of the evolution of color vision has benefited greatly from the use of comparative phylogenetic studies. These studies can use the evolutionary relationships among different organisms (represented in phylogenetic trees) to examine the evolution of color vision in relation to the context in which it may have evolved. Even though it is possible to determine how color vision benefits an organism in the present, current function does not necessarily tell us when or in what context color vision initially evolved (Gould and Vrba 1982; Greene 1986; Baum and Larson 1991). Determining the performance advantage that initially selected for color vision requires evidence of phylogenetic congruence between the origin of color vision and the performance advantage (Greene 1986). So, for example, a comparative phylogenetic study was used to determine if primates evolved trichromatic color vision as a means of finding red fruits among the green foliage or to find high-quality mates (see Fig. 3).

\section{The Consequences of Color Vision}

Color vision provides organisms with important sensory information about their environment. For instance, the ability to distinguish colors allows organisms to detect and recognize two very important objects - food and mates. What colors animals can detect will influence their ability to forage and hunt, avoid predators, and select quality mates. Here we review a few key examples of each of these different consequences of color vision. In addition, as not all of the consequences of color vision are beneficial, we examine the tradeoffs associated with color vision, which could help explain why not all animals have the ability to detect colors.

\section{Color Vision Improves Foraging}

The relationship between insects and flowering plants is one of the classic examples of coevolution. Plants use insects to transfer pollen from plant to plant, thus helping plants with sexual reproduction. Insects are willing intermediaries, as they are rewarded for their behavior with either nectar or pollen. While we may find the bright colors of flowers aesthetically pleasing, we cannot actually see many of the colors flowers emit, as these colors have evolved for receivers with color vision that is not the same as ours. In many cases, the intended receiver is an insect. The color vision of insects allows them to detect important signals produced by flowering plants. So, for example, in at least 74 different families of flowering plants (angiosperms), the flowers undergo dramatic color changes which signal to insects when they have nectar rewards. Researcher Martha Weiss compared the nectar volume, condition of the stigma (female receptacle of the flower), and pollen availability of pre- and postchange flowers and found that prechange flowers offered nectar rewards and were sexually viable, while postchange flowers did not offer nectar, lacked pollen, and appeared nonreceptive (Weiss 1991). Therefore, for an insect visit to benefit the flower, the best time of the visit would be when the flower has pollen and is sexually viable. It appears that plants signal when they are in this stage. What is important from the point of view of the insect is that this is also the time that plants produce the most nectar, and sure enough, Weiss found that insects concentrated their visits on prechange flowers. These results suggest that because the insects can detect color change in the flowers, both the insects and the plants benefit.

Color changes are also used by plants to tell birds and other frugivores when their fruits are ripe and ready to be eaten so the seeds can be dispersed (Wheelwright and Janson 1985). In many cases, red is the color of fruit that is ripe (e.g., apples, berries, etc.). Is this an example of "true" interspecific communication that benefits both parties? From the plants' point of view, having animals eat their fruits is a great way of dispersing the seeds found within the fruit. In some cases, if the animal swallows the seeds, the seeds are deposited some distance away from the parent 
along with some "fertilizer" to help the seed grow. The danger for the plant is if the animal eats the fruit too early before the seeds are developed and ready to go out on their own. The color change in fruits coincides with the timing of the development of the seeds and is the signal that the fruit is ready to be eaten. Most plants have evolved a way to be sure that animals pay attention to this signal by keeping the sugars animals want in the form of acids until the fruit is ripe. Therefore, color vision that allows an animal to detect when a fruit is ripe would be clearly beneficial, suggesting that the colors of fruit are a signal in a system involving true communication between plants and animals.

\section{In What Context did Trichromatic Color Vision Evolve in Primates?}

Another advantage to being able to distinguish between the colors red and green (trichromatic color vision) would be to detect red fruits against the background of green foliage. Primates are unique among mammals in that most have trichromatic color vision. It has been hypothesized that being able to detect red fruits against a green background is the reason that trichromatic color vision evolved in primates (reviewed by Surridge et al. 2003). When scientists consider which hues individuals with trichromatic vision can see, they have argued that trichromatic phenotypes are better suited than dichromats at discriminating ripe fruit hues (red, orange, and yellow; Regan et al. 2001; although see Riba-Hernandez et al. 2004) and young red leaves (Lucas et al. 1998) from nonripe fruits and leaf background. The behavioral evidence, however, is mixed. While some studies have found that primates with trichromatic vision do appear to forage more efficiently, other field studies have not (Dominy et al. 2003; Dominy 2004). Were benefits due to increased foraging efficiency the driving selection behind the initial evolution of trichromatic color vision in primates?

The competing hypothesis is that trichromatic color vision evolved in the context of sexual selection as a means for communication between individuals of the same species. Several studies have noted that primates use red colors for intraspecific signaling (reviewed by Surridge et al. 2003, Fig. 2). Changizi et al. (2006) suggested that because the color vision in some primates is near-optimal for discriminating skin color modulations, trichromacy was originally selected for the perception of skin color signaling.

Determining the current function of a trait like color vision, however, is not the best way to establish the context in which the trait initially evolved. If being able to see red traits on conspecifics is what drove the evolution of red/ green color vision, then red traits should have evolved at the same time as or earlier than red/green color vision. If trichromatic color vision evolved before red traits, it does

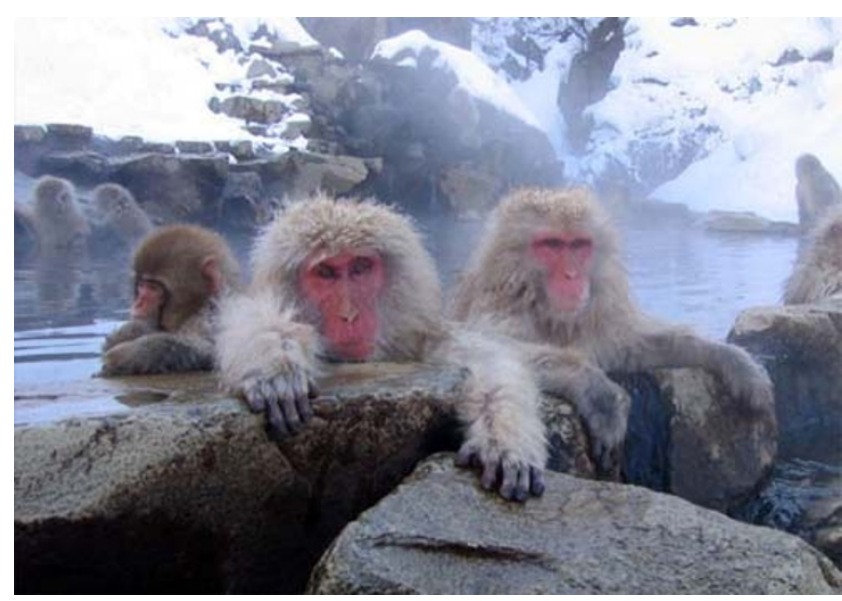

Fig. 2 The red faces on these Japanese macaques (Macaca fuscata), also known as the Snow Monkey, may provide information to potential mates about mate quality. In the rhesus macaque (Macaca mulatta), females prefer the red version of males' faces (Waitt et al. 2003). M. fuscata is a terrestrial Old World monkey species native to Japan, shown here relaxing in naturally heated volcanic hot springs. Photo courtesy of Wikipedia

not suggest that it is not important for intraspecific communication, but just that the red traits took advantage of a preexisiting sensory bias to detect red. Mutations that made already red traits like skin more visible and attractive to potential mates would have been passed on more frequently.

Fernandez and Morris (2007) conducted phylogenetic analyses to test the hypothesis that trichromatic color vision in primates was a preexisting bias, evolving before the red traits used to communicate between conspecifics. They found that red/green color vision was present before the evolution of red traits (see Fig. 3). This is interesting because it argues that something other than being able to see red traits drove the evolution of color vision-possibly increased foraging efficiency. But their analyses also suggested that the red traits we see in many primate species evolved to take advantage of the ability of conspecifics to see the color red. In other words, red/green color vision was a preexisting sensory bias that male or female primates could have taken advantage of, thereby enticing potential mating partners to pay attention to them.

Not surprisingly, researchers have been interested in this bias for the color red in humans. One study has shown that across a range of sports, wearing red was consistently associated with a higher probability of winning (Hill and Barton 2005). Like many nonhuman species, it seems that humans use color to signal competitive advantage. This response was shown to be sex specific and suggests that men may associate red with aggression or dominance, similar to what is known for males in other species (Ioan et al. 2007). 
Fig. 3 Ancestral State Reconstruction using maximum likelihood and the stored MK1 model (i.e., equal likelihood) implemented in Mesquite. Areas of pies indicate relative support for ancestral states. a) color vision; trichromatic color vision, indicated in black, was present at Node 2 before the evolution of b) red skin, indicated in black, and red pelage (not shown). Pie charts with asterisks indicate significant support for ancestral state reconstruction at that node. Fernandez and Morris (2007) (C) 2007 American Naturalist

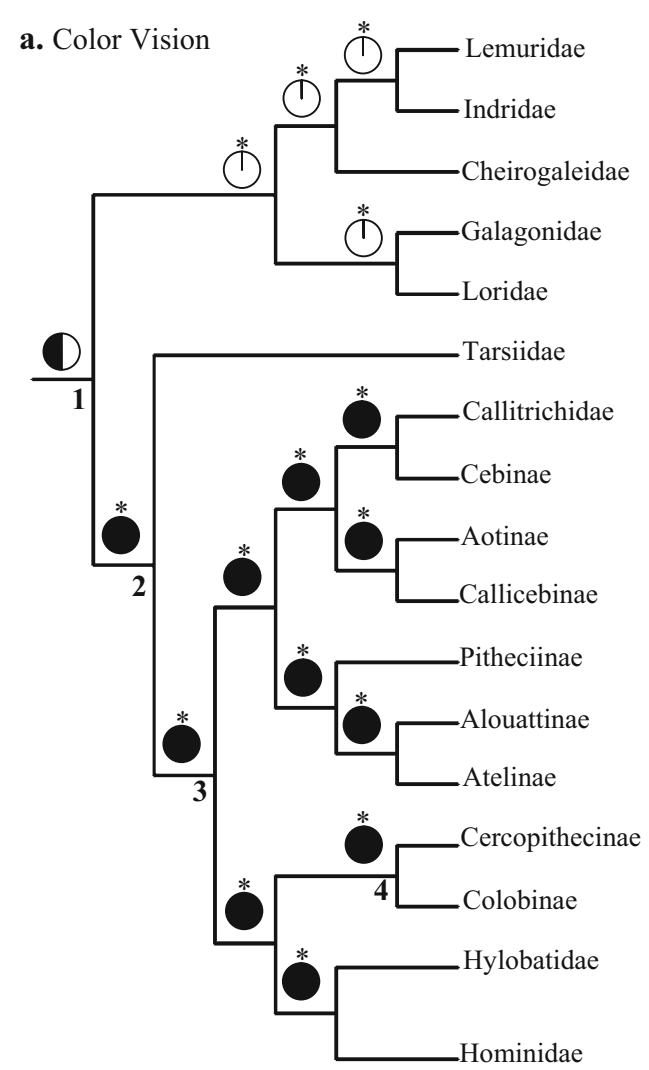

\section{Color Vision and Sexual Selection in Bowerbirds}

Colors as well as the specific patterns of different colors play a significant role in many animals' ability to find highquality mates of the right species. Sexual selection is a powerful evolutionary component of natural selection that provides some individuals with more mates than others due to either mate preference or competition for access to mates. John Endler et al. (2005) examined the evolution of colored plumage in bowerbirds. One of the interesting aspects of these Australian birds is that the males of some species also collect colored items to decorate their bowers (structures males build with sticks and grass as arenas for courting females) as a method of attracting females (Borgia 1997; Frith and Frith 2004). Females gain information about species identity and male quality by assessing the colors of a male's plumage and the colors of the items he placed in front of his bower (Frith and Frith 2004). Endler's study demonstrated how color pattern evolution is at least partially predictable based on the visual systems of these birds, as well as the different types of information encoded in the color patterns. By examining plumage dimorphism (difference between males and females), conspicuousness of plumage in relation to the visual background, and the use

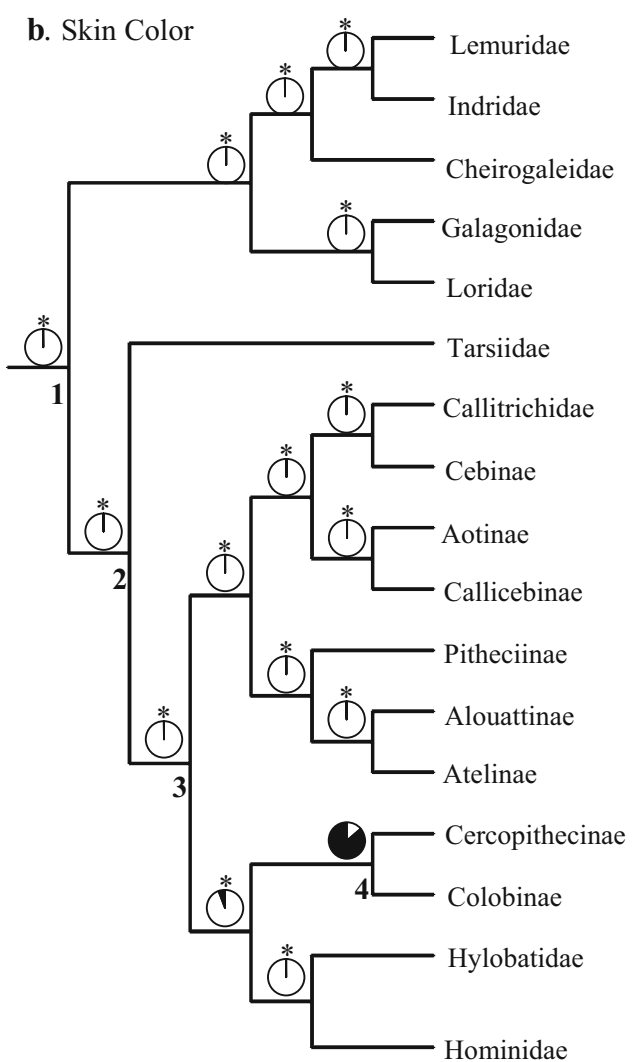

of colored objects in the bower in a phylogenetic context, Endler et al. (2005) found that the degree to which a species was sexually dimorphic both increased and decreased over evolutionary time in parallel with conspicuousness of their plumage and bower structure against the background. However, the conspicuousness of the colored ornaments added to the bowers always increased, suggesting that while there is sometimes a cost to having conspicuous plumage, possibly due to predation, having a bower that is conspicuous is not costly to the same extent.

\section{Color Vision and Sexual Selection in Cichlids}

When females from the same population have different mating preferences for a variable male trait, it is possible that sexual selection could facilitate speciation or the formation of two species from one. It has been hypothesized that sexual selection could be responsible for the large number of cichlid fish species that live in Lake Victoria in Africa. The difference in the nuptial colors of the males, or the colors they use to attract females of the right species during the breeding season, is tightly correlated with the wavelengths of the photopigments in the eyes of the females that allow them to see the colors of the males from their species. 
More than 500 species of cichlids are found in this large freshwater lake, and they exhibit some very interesting evolutionary patterns (Meyer 1993). First, it appears that the species' flock evolved from one or a few ancestral species over a rather short period of time (less than 16,500 years). Second, while there are a diverse number of morphologies found across these species that allow the fish to feed on different types of foods, the species that are most closely related have the same morphologies but very different male nuptial colorations. Male cichlids exhibit very vivid colors during the mating season (their nuptial colors) that are specific to a given species and are likely to serve as signals to help females identify mates of the right species. It turns out that photopigments can be very different in different species, suggesting that the eyes of individuals of the different species are specifically "tuned" to see the nuptial colors of the males from their species (Carleton et al. 2005). Behavioral studies that examine female mating preferences have shown that when you mask the color differences between males in the laboratory by using monochromatic light, the females show no preference between their own males and those of a closely related species (Mann et al. 2004). However, if you give the females the same choice with normal light where the different colors between the males can be detected, they prefer their own males over heterospecies.

Whereas the above data suggests a role for sexual selection in producing the large number of species of cichlids in Lake Victoria, Ole Seehausen and colleagues wanted to test this idea further (Terai et al. 2006). They wanted to see if they could find a population of cichlid fishes where they could detect the initial variation in female preference necessary for the process of speciation. Once females have variation in preference, the population could become reproductively isolated in two groups: the females that prefer one type of males and the males of that type, compared to the females that prefer the other type of males and the males with those traits. Over time, if there is little to no inbreeding between the two groups, they would evolve separately and form two species from one. The researchers studied a species of cichlid where the males varied in their nuptial colors from reddish to blue. What they found was that some females had a consistent preference for red males and some for blue males. If these preferences were to result in assortative mating in the field (females with red preferences mating with the reddish males only, females with blue preferences mating with the blue), sexual selection in the form of variation in female mating preferences could result in the formation of new species. Terai, et al. (2006) demonstrated that divergent evolution of the visual system in two clades of cichlid fishes coincides with divergence in male breeding coloration. These results add further support to the hypothesis that natural selection, acting on the visual systems of these fish, has led to the formation of new species through sexual selection.

\section{Some Tradeoffs}

Animals can process only so much sensory information at one time. In addition, some environments, such as the nighttime, do not offer an organism's color information. So while the evolutionary shift to color vision undoubtedly helped many animals mate, forage, and hunt for food or escape predators, among other activities, it also meant that there were tradeoffs. Tradeoffs, or compromises, are ubiquitous in evolution, as selection that favors one trait is often at the expense of another. So when considering other senses animals use to gain information about their environment, such as odor, nocturnal vision, and echolocation, researchers have questioned when and how the evolution of color vision has influenced these other sensory modalities.

For most mammals, odor is an important sense used to detect and distinguish between potential mates and competitors. At the very front end of the nasal cavity is a small organ called the vomeronasal organ (VNO) that detects pheromones, chemicals that are produced by one individual to trigger a behavioral response in another individual of the same species. The family of olfactory receptor genes that is essential for the function of VNO has been detected in mice (Stowers et al. 2002; Leypold et al. 2002). These same genes can be found across all mammals, and in many primates like ourselves they are pseudogenes, or nonfunctional (Gilad et al. 2004). Using phylogenetic analyses that examine the evolutionary relationships between species that have this family of genes and those that do not, it is possible to determine when in our evolutionary history the genes became nonfunctional. In addition, molecular evidence of positive selection on these important VNO genes can be used to determine if the VNO is functioning or not. Both lines of evidence suggest that the VNO became nonfunctional at the same time in primate evolution that trichromatic color vision evolved via a gene duplication of the green/red opsin gene (Liman and Innan 2003). What this suggests is that when primates increased their ability to distinguish red and green, they reduced their reliance on chemical signals. In general, we know that animals can only process so much information at one time, and in many cases, use stimulus filtering to limit the amount of sensory information that needs to be processed. In the case of primates that evolved the ability to distinguish red from a green background, it appears that the information that had previously been provided through chemical cues or signals became less important, so that selection on the genes that keeps the VNO functional was relaxed. 
In some marine mammals, evolutionary conditions led to the loss of the short(S)-wavelength cones, a trait that researchers suggest is related to the marine environment. Leo Peichl and his colleagues studied a sample of seven species of toothed whales and five species of marine carnivores - eared and earless seals - to try to understand why the marine mammals have only L-cones, or longwavelength photoreceptors, and thus are essentially color blind (Peichl et al. 2001). In contrast, the wolf, ferret, and European river otter and hippopotamus - animals considered close terrestrial relatives of the seals and whales-have the normal mix of S and L cones. The loss of the S-cones in marine species from both whales and pinnipeds suggests there was an adaptive evolutionary advantage. But why should this be so in a marine visual environment where the light of clear ocean waters increasingly shifts to a blue range, or short wavelength, with depth? Also, while cone monochromacy would not seem to hurt animals that are largely nocturnal, it seems losing the S-cone would be disadvantageous for whales and seals, whose habitat includes the bright surface of the ocean.

By performing postmortem studies of eyes obtained from animals that had died or had been euthanized in wildlife sanctuaries, the researchers confirmed the absence of S-cones in these marine mammals and showed in all cases that the rod photoreceptors of the marine animals outnumbered the cones. The presence of rod-dominated retinas helps to explain these mammals' good vision in dim light activities, such as for deep diving and nighttime foraging. It also points to a possible functional explanation for the S-cone loss. In mammals, rods and cones vie for the same surface on the retina. The researchers noted that if one system is favored, the other one might be reduced. In a similar vein, perhaps the S-cone loss represents an economical adaptation: simplifying the retina and the complexity of information processed there might have freed up cortical space for other sensory abilities.

In conclusion, the scientists hypothesize that the S-opsin loss is likely a phylogenetically old event, occurring early in marine mammal evolution. The adaptive advantage might be related to something that occurred then, not something we see in their present lifestyles. When these marine mammals' ancestors moved from terrestrial life to the sea, they inhabited coastal waters, where the underwater light field differs from the ocean depths as a result of organic and inorganic material from land. In this environment, the loss of S-cones, or ability to see a blue range, would not be such a disadvantage. This would help explain why close relatives such as the river otter retained the S-cones, since they continued to live in shallow coastal marine habitats. The researchers describe a possible tradeoff: "Cone monochromacy may have been the price these mammals paid for access to the abundance of food in deeper waters (Peichl et al. 2001)."
An animal's visual abilities may be related to energy expenditure. Tamara Frank, a visual ecologist at the Harbor Branch Oceanographic Institution in Florida, has studied the vision of deep-sea animals that inhabit water depths where sunlight does not penetrate and where the longwavelength red light is absorbed by the upper layers of water. Of those deep-sea animals that have been studied, most appear to see light in the blue-green spectrum and do not see red light (Schrope 2007). And yet benthic species have enlarged eyes, larger than related species that occupy the water column above them, Frank said in a phone interview. Large eyes have the benefit of collecting more light, but there is a cost to this advanced vision due to their increased weight. Unlike animals in ocean habitat who must expend a great deal of energy remaining buoyant and out-swimming predators, the extra weight is less costly to bottom-dwellers that can sit on the bottom and hide from predators among rocks and sediments.

Many animals use bright colors to communicate, and yet there is often a tradeoff between communicating with conspecifics and being conspicuous to predators. Justin Marshall notes that because of this tradeoff, more than one "evolutionary pressure" exists to explain the stunning and varied colors of reef fishes (Marshall 2000). He examined the function of the colors of reef fish by measuring the fish and their habitats using a spectrophotometer, and he determined in which habitats they would be conspicuous, based on information about the visual systems of the fish. He found that some colors are used for different jobs under different circumstances, from communication with potential mates to camouflage from predators. He examined two species of damselfish, the blue-green Chromis viridis and the yellow Pomacentrus moluccensis, that live in and around the same heads of coral. Spectral data suggested that the yellow of reef fish is a good match to the color of the coral, while the blue is a good wavelength match to the open ocean. Both species of fish respond to serious threats of predation by hiding within the branching coral. However, with what is perceived as a lesser predation threat, such as the slow approach of a diver, the yellow species hovers just above the coral, while the blue species forms a school above the yellow where they would fade into the color of their background. Therefore, the bright blue and yellow colors that are so common in reef fish are good for camouflage or communication depending on the background they are viewed against.

\section{Studying the Unexpected}

The quest to better understand color vision evolution often leads scientists to consider the unusual, those animals whose visual capabilities defy expectations. The following are examples of a few animals whose fascinating visual 
systems do not appear particularly well-adapted to their environment. Indeed, we are still being surprised by what we are learning.

For instance, a recent study considered whether an animal that is fully nocturnal requires color vision. Researchers looked at the molecular makeup of the visual system of the endangered aye-aye, the world's largest nocturnal primate. A Madagascar native, these primates split from other groups including humans, apes, and monkeys more than 60 million years ago. The results of genetic analyses of DNA samples from eight ayes-ayes were surprising. Expecting that the opsin genes of a nocturnal animal that does not need color vision to operate in a nighttime environment would have mutated or degraded, the researchers discovered the opposite: the opsin genes appeared to be fully functional. While it is apparent that the aye-ayes have the genetic hardwiring to see colors, it is still unknown if they do. Future behavioral studies may help to determine if the aye-ayes respond to colors (Perry et al. 2007).

We once thought animals could not see colors at night. But research has shown that a night-active vertebrate, the helmet gecko, not only sees color, it uses cone-based color vision to see in dim moonlight situations when humans are colorblind. The gecko is unusual among nocturnal vertebrates, for it has no rods, but three cone types sensitive to ultraviolet, blue, and green light. In contrast, almost all vertebrates have a dual system with multiple cones and a single rod; the nocturnal species typically have higher rod ratios. Thus, nocturnal geckos have lost the red-sensitive cone but adapted to their dim-lit environment and still retained color vision. Researchers Roth and Kelber, who note that only nocturnal moths have been found to share the geckos' nighttime color vision ability, suggest that geckos exploit it to forage for wellcamouflaged food, navigate landmarks, and find partners (Roth and Kelber 2004).

Some organisms, like the cuttlefish that Woods Hole senior scientist Roger Hanlon studies, are camouflage experts that can transform their body's coloration from high-contrast checkerboard patterns to subtle hues that match the environment (Zimmer 2008). It seems they must be able to see colors to be so colorful themselves. But the evidence says they cannot. Even Hanlon, who has hundreds of photos showing their color matches to background, thought they should be able to see colors. But he noted that they "flunked" a behavioral assay for color vision (Mäthger et al. 2006). "The cephalopods can work in a colorful world like a coral reef-avoid predators with phenomenal color and night vision and communicate with conspecificswithout being able to discriminate color themselves," he said in a phone interview. So Hanlon and his colleagues are looking at a number of mechanisms - other than color vision - to help explain the cephalods' colorful camouflage patterns. One such mechanism involves a possible hidden communication channel that employs polarized light, which cephalopods and stomatopods can see. His research shows that the reflectors in the skin of the cuttlefish not only provide colorful iridescence but also reflect off polarized light. Perhaps the cuttlefish send polarized signals to conspecifics at the same time that their camouflage tricks predators like fish, most of which are not sensitive to polarized light (Mäthger and Hanlon 2006).

Along with Hanlon, a number of color vision researchers are exploring the existence of multiple photodetection systems and other mechanisms by which animals extract information from light.

\section{Conclusion}

In recent decades, scientists have looked intensely at the visual system of vertebrates, and perhaps "myopically focused on rod and cone photoreceptors and the visual information they deliver," researcher Russell D. Fernald noted in a Science review (Fernald 2006). But that focus has expanded. Researchers now are certain to bring the science of genomics, phylogenetics, animal behavior, and neurology to the discussion. We are likely to learn more about parallel sensory pathways, discover new opsin genes, or find old ones in new places and, overall, gain a better understanding of how animals, including humans, see and use colors to forage, survive, and mate.

Acknowledgements The authors wish to thank Samir Deeb, Tamara Frank, and Roger Hanlon for granting phone interviews.

\section{Key definitions}

Opsins

the protein that makes up the

Rods photopigments found in rods and cones photopigment rhodopsin and are sensitive to low light

Cones the cells in the retina that contain photopigments with overlapping absorption spectra allowing for color perception.

Allele an alternative form of a gene (one member of a pair), located at a specific position on a specific chromosome.

Heterozygotes having two different alleles for the same gene.

Gene family a set of related genes, almost certainly formed by duplication of an ancestral gene, and having a recognizably similar sequence. The globin gene family is an example. 


\section{References}

Baum DA, Larson A. Adaptation reviewed a phylogenetic methodology for studying character macroevolution. Syst Zool. 1991;40:1-18. doi:10.2307/2992218.

Bennett ATD, Cuthill IC, Norris KJ. Sexual selection and the mismeasure of color. Am Nat. 1994;144:848-60. doi:10.1086/285711.

Borgia G. Comparative behavioral and biochemical studies of bowerbirds and the evolution of bower-building. In: Reaka-Kudia ML, Wilson DE, Wilson EO, editors. Biodiversity. Vol. II. Understanding a protecting our biological resource. Washington DC: Joseph Henry Press; 1997.

Carleton KL, Parry JWL, Bowmaker JK, Hunt DM, Seehausen O. Color vision and speciation in Lake Victoria cichlids of the genus Pundamilia. Mol Ecol. 2005;14:4341-53.

Carroll J, Murphy CJ, Neitz M, Hoeve JN, Neitz J. Photopigment basis for dichromatic color vision in the horse. J Vis. 2001;1:80 7. doi:10.1167/1.2.2.

Changizi MA, Zhang Q, Shimojo S. Bare skin, blood and the evolution of primate colour vision. Biol Lett. 2006;2:217-21. doi:10.1098/rsbl.2006.0440.

Deeb SS, Motulsky AG. Molecular genetics of human color vision. Behav Genet. 1996;26:195-207. doi:10.1007/BF02359380.

Dominy NJ. Color as an indicator of food quality to anthropoid primates: ecological evidence and an evolutionary scenario. In: Ross CF, Kay RF, editors. Anthropoid origins: new visions. New York: Kluwer Academic; 2004. p. 615-35.

Dominy NJ, Garber PA, Bicca-Marques JC, Azevedo-Lopes MA. Do female tamarins use visual cues to detect fruit rewards more successfully than do males? Anim Behav. 2003;66:829-37. doi:10.1006/anbe.2003.2288

Endler JA. A predator's view of animal color patterns. Evol Biol. 1978;11:319-64.

Endler JA. On the measurement and classification of colour in studies of animal colour patterns. Biol J Linn Soci. 1990;41:315-52. doi:10.1111/j.1095-8312.1990.tb00839.x.

Endler JA, Westcott DA, Madden JR, Robson T. Animal visual systems and the evolution of color patterns: sensory processing illuminates signal evolution. Evolution Int J Org Evolution. 2005;59:1795-818.

Fernald RD. Casting a genetic light on the evolution of eyes. Science. 2006;313:1914. doi:10.1126/science.1127889.

Fernandez AA, Morris MR. Sexual selection and trichromatic color vision in primates: statistical support for the pre-existing bias hypothesis. Am Nat. 2007;170:10-20. doi:10.1086/518566.

Frith CB, Frith DW. The bowerbirds. New York: Oxford Univ. Press; 2004.

Gilad Y, Wiebe V, Przeworski M, Lancet D, Pääbo S. Loss of olfactory receptor genes coincides with the acquisition of full trichromatic vision in primates. PLoS Biol. 2004;2:120-5. doi:10.1371/journal.pbio.0020005.

Gould SJ, Vrba ES. Exaptation: a missing term in the science of form. Paleobiology. 1982;8:4-15.

Greene HW. Diet and arboreality in the emerald monitor, Varanus prasinus, with comments on the study of adaptation. Fieldiana Zool. 1986;31:1-12.

Hill RA, Barton RA. Red enhances human performance in contests. Nature. 2005;435:293. doi:10.1038/435293a.

Hubel DH. Eye, brain, and vision (Scientific American Library No.22). New York: W.H. Freeman; 1988. Also online.

Ioan S, Sandulache M, Avramescu S, Ilie A, Neacsu A, Zatrean L, et al. Red is a distractor for men in competition. Evol Hum Behav. 2007;28:285-93. doi:10.1016/j.evolhumbehav.2007.03.001.

Jacobs GH. The distribution and nature of color vision among the mammals. Biol Rev Camb Philos Soc. 1993;68:413-71. doi:10.1111/j.1469-185X.1993.tb00738.x.
Jacobs GH, Williams GA, Cahill H, Nathans J. Emergence of novel color vision in mice engineered to express a human cone photopigment. Science. 2007;315:1723-5. doi:10.1126/science.1138838.

Jameson KA, Highnote SM, Wasserman LM. Richer color experience in observers with multiple photopigment opsin genes. Psychon Bull Rev. 2001;8:244-61.

Leypold BG, Yu CR, Leinders-Zufall T, Kim MM, Zufall F, Axel R. Altered sexual and social behaviors in trp2 mutant mice. Proc Natl Acad Sci USA. 2002;99:6376-81. doi:10.1073/pnas.082127599.

Liman ER, Innan H. Relaxed selective pressure on an essential component of pheromone transduction in primate evolution. Proc Natl Acad Sci USA. 2003;100:3328-32. doi:10.1073/pnas.0636123100.

Lucas PW, Darvell BW, Lee PKD, Yuen TDB, Choong MF. Colour cues for leaf food selection by long-tailed macaques (Macaca fascicularis) with a new suggestion for the evolution of trichromatic colour vision. Folia Primatol (Basel). 1998;69:139_ 52. doi:10.1159/000021576.

Maan ME, Seehausen O, Soderberg L, Johnson L, Ripmeester EAP, Mrosso HDJ, et al. Intraspecific sexual selection on a speciation trait, male coloration, in the Lake Victoria cichlid Pundamilia nyererei. Proc R Soc Lond B Biol Sci. 2004;271:2445-52. doi:10.1098/rspb.2004.2911.

Marshall NJ. Communication and camouflage with the same "bright" colours in reef fishes. Philos Trans R Soc Lond B Biol Sci. 2000;355:1243-8. doi:10.1098/rstb.2000.0676.

Mäthger LM, Hanlon RT. Anatomical basis for camouflaged polarized light communication in squid. Biol Lett. 2006;2:494-6. doi:10.1098/rsbl.2006.0542.

Mäthger LM, Barboas A, Miner S, Hanlon RT. Color blindness and contrast perception in cuttlefish (Sepia officinalis) determined by a visual sensorimotor assay. Vision Res. 2006;46:1746-53. doi:10.1016/j.visres.2005.09.035.

Meyer A. Phylogenetic relationships and evolutionary processes in east African cichlid fishes. Trends Ecol Evol. 1993;8:279-84. doi:10.1016/0169-5347(93)90255-N.

Merbs SL, Nathans J. Photobleaching difference absorption spectra of human cone pigments: quantitative analysis and comparison to other methods. Photochem Photobiol. 1992;56:869-81. doi:10.1111/j.1751-1097.1992.tb09708.x.

Miller PE, Murphy CJ. Vision in dogs. J Am Vet Med Assoc. 1995;207:1623-34.

Neitz J, Geist T, Jacobs GH. Color vision in the dog. Vis Neurosci. 1989;3:119-25.

Neitz M, Kraft TW, Neitz J. Expression of L-cont pigment gene subtypes in females. Vision Res. 1998;38:3221-5. doi:10.1016/ S0042-6989(98)00076-5.

Peichl L, Behrmann G, Krögerm RHH. For whales and seals the ocean is not blue: a visual pigment loss in marine mammals. Eur J Neurosci. 2001;13:1520-8. doi:10.1046/j.0953-816x.2001.01533.x.

Perry GH, Martin RD, Verrelli BC. Signatures of functional constraint at aye-aye opsin genes: the potential of adaptive color vision in a nocturnal primate. Mol Biol Evol. 2007;24(9):1963-70. doi:10.1093/molbev/msm124.

Piantanida T. Genetics of inherited colour vision deficiencies. In: Foster DH, editor. Inherited and acquired colour vision deficiencies, vision and visual dysfunction, volume 7. Boca Raton FL: CRC Press; 1991. p. 98-9.

Regan BC, Juliot C, Simmen B, Viénot F, Charles-Dominique PC, Mollon JD. Fruits, foliage and the evolution of primate color vision. Philos Trans R Soc Lond B Biol Sci. 2001;356:229-83. doi:10.1098/rstb.2000.0773.

Riba-Hernández P, Stoner KE, Osorio D. Effects of polymorphic colour vision for fruit detection in the spider monkey Ateles geoffroyi, and its implications for the maintenance of polymorphic colour vision in platyrrhine monkeys. J Exp Biol. 2004;207:246570. doi:10.1242/jeb.01046. 
Roth LSF, Kelber A. Nocturnal colour vision in geckos. Biol Lett. 2004;271:S485-7.

Schrope M. Marine biology: lights in the deep. Nature. 2007;450:4724. doi:10.1038/450472a.

Stowers L, Holy TE, Meister M, Dulac C, Koentges G. Loss of sex discrimination and male-male aggression in mice deficient for TRP2. Science. 2002;295:1493-500. doi:10.1126/science.1069259.

Surridge AK, Osorio D, Mundy NI. Evolution and selection of trichromatic vision in primates. Trends Ecol Evol. 2003;18:198205. doi:10.1016/S0169-5347(03)00012-0.

Terai, Y, Seehausen, O, Sasaki, T, Takahashi, K, Mizoiri, S, Sugawara, T, Sato, T, Watanabe, M, Konijnendijk, N, Mrosso, H. D. J., Tachida, H, Imai, H, Schichida,Y., Okada, N. Divergent selection on opsin drives incipient speciation in Lake Victoria Cichlids. PLOS 2006; 4: (open access)

Waitt C, Little AC, Wolfensohn S, Honess P, Brown AP, BuchananSmith HM, et al. Evidence from rhesus macaques suggests that male coloration plays a role in female primate mate choice. Proc R Soc Lond B Biol Sci. 2003;270:S144-6. doi:10.1098/rsbl.2003.0065.

Weiss M. Floral colour changes as cues for pollinators. Nature. 1991;354:227-9. doi:10.1038/354227a0.

Wheelwrigh NT, Janson CH. Colors of fruit display of bird-dispersed plants in two tropical forests. Am Nat. 1985;126:246-51.

Winderickz J, Lindsey DT, Sanocki E, Teller DY, Motulsky AG, Deeb SS. Polymorphism in red photopigment underlies variation in colour matching. Nature 1992;356:431-3. April 2.

Zaccardi G, Kelber A, Sison-Mangus MP, Briscoe AD. Color discrimination in the red range with only one long-wavelength sensitive opsin. J Exp Biol. 2006;209:1944-55. doi:10.1242/jeb.02207.

Zimmer C. Revealed: Secrets of the Camouflage Masters. New York Times Feb 19, 2008. D1, D4.

\section{Resources}

http://www.mbl.edu/mrc/hanlon/video.html

$\mathrm{http}: / /$ hubel.med.harvard.edu

Island of the Color Blind: Monochromatism. Oliver W. Sacks. Video, Mind Traveler Series; Princeton, N.J.: Films for the Humanities \& Sciences: BBC Worldwide America 1998

www.colormatters.com

\section{Genetics of Human Color Vision}

There are two types of photoreceptors in the human retina, rods and cones. The four proteins that make up the photopigments found in these cells are coded for by a family of genes, which means the genes are derived from a common ancestral gene. The rods have a pigment called rhodopsin, and are sensitive to low light levels. Each class of cone has a distinct photopigment with particular absorption spectra. The spectra characteristics of the visual pigments in the cones of humans have been confirmed by several different methods (Merbs and Nathans 1992). The three photopigments are called SWS (short wavelength spectra), with a maxima of approximately $420 \mathrm{~nm}$; medium wavelength spectra (MWS), with an absorption spectra of approximately $530 \mathrm{~nm}$; and long wavelength spectra (LWS), with an absorption spectra of approximately $560 \mathrm{~nm}$. The genes that code for MWS and LWS are very similar to one another and are found next to each other on the long arm of the $\mathrm{X}$ chromosome. These genes were most likely produced by gene duplication, which happens when there is an unequal crossover event, in this case between the two $\mathrm{X}$ chromosomes. Once a gene is duplicated, the identical genes can undergo changes and diverge to create two different genes (i.e., MWS and LWS).

Individuals who have all three functioning opsin genes should have the three classes of photopigments in their cones and are called trichromats. Individuals that lack either LWS or MWS cone function are dichromats or more commonly known as being red/green "color blind." In a behavioral test known as the Nagel anomaloscope, an individual is asked to match mixtures of red and green light on one side, to yellow light on the other. People who are color blind will match the yellow light with any mixture of red and green, including red and green alone. In other words, they cannot distinguish red from green. Approximately, $8 \%$ of the male European population has redgreen color defects (Piantanida 1991), while only $0.5 \%$ Caucasian females are color blind. These percentages differ depending on race (i.e., In the Asiatic population, $5 \%$ of males are color blind and $0.5 \%$ of females), but due to the location of the genes that code for LWS and MWS on the X chromosome, the number of females that are color blind is fewer than males across all populations of humans.

In some cases, the LWS gene is slightly different on the two $\mathrm{X}$ chromosomes (different alleles), and therefore females can be tetrachromatic (have four different photoreceptors) if they are heterozygotes for this gene (see Fig. 1b). As males only have one X chromosome, they can only be trichromatic or, in some cases, dichromatic. Even though half of the $\mathrm{X}$ chromosomes in a female become inactivated, if this is random in relation to the allele on the $\mathrm{X}$ for LWS, heterozygous females will have patches of cones with one or the other of the LWS photopigments. Behavioral studies have found that these females can detect more colors than females or males that are trichromatic (Jameson et al. 2001). The two different LWS alleles also means that trichromatic males and females will differ in their perception of red light, depending on which LWS allele is on the $\mathrm{X}$ chromosome.

For further review of the genetics of human color vision see Deeb and Motulsky (1996). 